\title{
Prolonged stress causes depression in frontline workers facing the COVID-19 pandemic. A repeated cross-sectional study.
}

\author{
Nicola Magnavita ${ }^{1,2, *}$, Paolo Maurizio Soave 1,3 , and Massimo Antonelli ${ }^{3}$ \\ 1 Postgraduate School of Occupational Medicine, Università Cattolica del Sacro Cuore, 00168 Rome, Italy; \\ nicola.magnavita@unicatt.it; \\ 2 Department of Woman/Child \& Public Health, Fondazione Policlinico Universitario Agostino Gemelli \\ IRCCS, 00168 Rome, Italy; nicola.magnavita@policlinicogemelli.it \\ 3 Department of Emergency, Anesthesiology and Resuscitation Sciences, Fondazione Policlinico \\ Universitario Agostino Gemelli IRCCS, 00168 Rome, Italy; massimo.antonelli@unicatt.it; \\ paolomaurizio.soave@policlinicogemelli.it \\ * Correspondence: nicolamagnavita@gmail.com; Tel.: +39-3473300367
}

\begin{abstract}
The Covid-19 pandemic has severely tested the mental health of frontline health care workers. A repeated cross-sectional study can provide information on how their mental health evolved during the various phases of the pandemic. The intensivists of a COVID-19 hub hospital in Rome were investigated with a baseline survey during the first wave of the pandemic in April 2020, and were contacted again in December 2020, during the second wave. 152 of the 205 eligible workers responded to an online questionnaire designed to measure procedural justice, occupational stress (effort / reward imbalance), sleep quality, anxiety, depression, burnout, job satisfaction, happiness, and turnover intention. Workers reported a further increase in workload and compassion fatigue, which had already risen during the first wave, and a marked reduction in the time devoted to meditation and mental activities. A low level of confidence in the adequacy of safety procedures and the need to work in isolation, together with an increased workload and lack of time for meditation were the most significant predictors of occupational stress in a stepwise linear regression model. Occupational stress was, in turn, a significant predictor of insomnia, anxiety, low job satisfaction, burnout, and intention to leave the hospital. The number of workers manifesting symptoms of depression increased significantly to exceed $60 \%$. Action to prevent occupational risks and enhance individual resilience cannot be postponed.
\end{abstract}

Keywords: emergency; infectious disease; organizational justice; stress; loneliness; compassion fatigue; meditation; prayer; insomnia; mental health; perspective study

\section{Introduction}

The pandemic of coronavirus disease 2019 (COVID-19), caused by severe acute respiratory syndrome coronavirus 2 (SARS-CoV-2), has dramatically tested health services all over the world. Since being hit by the first wave of the epidemic in the spring of 2020 [1] and the second wave in the autumn of the same year [2], Italy has been one of the countries most affected. For health care workers (HCWs) the two waves posed different problems. In the first phase of the outbreak, the sudden overload of work, the lack of protective equipment, fear of infection, insufficient knowledge of safety procedures and uncertainty about treatment criteria were among the major problems $[3,4]$. In the second phase, once the shortage of devices had been resolved, the new safety procedures had been assimilated and the therapeutic protocols had been consolidated, the psychosocial problems related to the on-going epidemic became evident. At the same time, public opinion towards HCWs was beginning to rapidly move in a more negative direction [5]. 
Since the early months of the COVID-19 epidemic, numerous scientific papers have considered the possibility that frontline HCWs are being affected by post-traumatic stress, anxiety, depression, and burnout. Extensive research has also led to a large number of systematic reviews and metaanalyses [6-8]. However, all the studies included in these reviews were cross-sectional or, at best, retrospective. Psychic symptoms in HCWs were generally compared to "normal values", administrative staff, or external samples; moreover, many studies lacked a control group [9]. Overall, a lack of longitudinal studies made it impossible to distinguish the effect of the pandemic from that of all other pre-existing stressors in hospital work, and there is still little evidence of an increase in mental health problems in HCWs during the outbreak. A repeated cross-sectional study will therefore help to determine how the mental health of frontline workers evolved during the different phases of the pandemic.

In this article we report the results of a repeated cross-sectional study on the frontline workers of one of the two Covid-19 hub hospitals in Latium, Italy. The baseline survey, conducted during the first wave of the pandemic (April-May 2020), found that most workers reported high work-related stress; one out of three reported insomnia; one out of four experienced anxiety, and the majority reported depressive symptoms [10]. The workers expressed a modest level of confidence in their safety measures and reported a significant reduction in physical activity, meditation and relaxation the commonest ways of increasing resilience. Younger trainee workers (residents) expressed a significantly lower level of confidence in prevention measures than anesthesiologists, and this lack of organizational justice was associated with increased occupational stress [11].

Six months after that study, when the second wave of infections was producing its effects, we set out to assess the condition of the workers who had continued to work in the hub hospital. This investigation was carried out before the start of the vaccination campaign. Our primary objectives were to assess the wellbeing and mental health of the workers after the first ten-month struggle with the virus and to evaluate the extent to which their attitude towards the pandemic had changed. Our ultimate aim was to identify the measures that would be most effective in preventing prolonged stress from impairing the health of workers.

\section{Materials and Methods}

\subsection{Participants}

All the workers in the anesthesiology department of the "A. Gemelli" University hospital in Rome $(n=205)$ who were directly involved in caring for suspected or confirmed cases of COVID-19 were emailed to invite them to participate in our survey. Their answers were collected anonymously on the SurveyMonkey® online platform. Participation was completely voluntary and not economically incentivized. Participants were enrolled between December 14, 2020 and January 5, 2021. A reminder mail was sent twelve days after commencing the investigation.

152 of the 205 eligible workers completed the survey (participation rate $=74.1 \%$ ). Participants were mainly young $(70.4 \%$ under 35 years of age), female $(93,61.2 \%)$ workers. Of those taking part, 105 were physicians and 47 were nurses (30.9\%). About a quarter of the participants $(34,22.4 \%)$ had been working in the hospital for less than one year; about a quarter $(42,27.6 \%)$ had worked there for 1-3 years, and half of the participants $(76,50 \%)$ had been employed in the hospital for more than three years. Many of the workers who had responded to the first survey conducted six months earlier, had quit their jobs. Over half of the participants $(87,57.2 \%)$ reported that they had participated in the previous survey.

Most participants $(80,52.6 \%$ ) reported unprotected exposure to SARS-CoV-2 patients (Table 1 ). Six of them reported having had a false positive antigen test at the periodic screening all hospital workers undergo, and 26 (17.1\%) had contracted Covid-19. Most of the workers who had contracted the infection had mild symptoms that did not require treatment $(16,61.5 \%)$ or were completely asymptomatic $(7,26.9 \%)$; only 3 had mild symptoms that required home treatment. 
Table 1. Characteristics of the population.

\begin{tabular}{ccccc}
\hline Variable & \multicolumn{2}{c}{$1^{\text {st }}$ wave } & \multicolumn{2}{c}{$2^{\text {nd }}$ wave } \\
\cline { 2 - 5 } & $\mathrm{N}$ & $\%$ & $\mathrm{~N}$ & $\%$ \\
\hline Gender, male & 85 & 47.2 & 59 & 38.8 \\
Age, $<$ 35 years & 104 & 57.8 & 107 & 70.4 \\
Physician & 154 & 85.6 & 105 & 69.1 \\
Reporting unprotected exposure to COVID-19 patients & 46 & 25.6 & 80 & 52.6 \\
Participated in the previous survey & - & - & 87 & 57.2 \\
Reporting a false-positive swab test & - & - & 6 & 3.9 \\
Reporting Covid-19 disease & - & - & 26 & 17.1 \\
\hline
\end{tabular}

The survey was conducted in accordance with the Helsinki Declaration. The Catholic University Ethics Committee approved the study (ID 3292).

\subsection{Questionnaire}

The questionnaire used in this study was similar to the one used in the previous survey. However, following the suggestions of a focus group composed of qualified anesthetists, some changes were made in order to identify specific conditions of the second phase of the epidemic.

The questionnaire was composed of 43 questions divided into 6 sections. The average time required for completion was 5 minutes. The questionnaire contained a section (11 items) regarding socio-demographic factors that could influence the outcome, e.g., gender, age class, length of service, type of work, and accident status (unprotected contacts with Covid-19 cases, positive oropharyngeal tests, previous infection). The second section (10 items) investigated the main changes in occupation and lifestyle caused by the epidemic.

Work-related stress was measured with the Italian version [12] of the "Effort Reward Imbalance" (ERI) questionnaire [13]. Responses were graded on a 4-point Likert scale from $1=$ "strongly disagree" to 4 = "strongly agree". The effort subscale was based on three questions (e.g., "My job has become more and more demanding"); the total score ranged from 3 to 12 . The reward subscale was based on seven questions (e.g., "I receive the respect I deserve from my superior or an equivalently qualified person"); consequently, this score ranged from 7 to 28 . Internal consistency reliability of the two effort and reward sub-scales in this study was 0.751 and 0.820 , respectively (good) [14]. The difference between efforts and results was measured as a weighted ratio of effort and reward. Values above one were considered indicative of distress.

The fourth section contained three questions on Procedural justice (PJ) regarding the regularity of safety procedures. This was measured using the Italian version [15] of the Colquitt Scale [16-18] by means of 3 items (e.g., "Are these procedures error-free?"). Each question was answered according to a 5 -point Likert scale, from $1=$ "I totally disagree" to $5=$ "I strongly agree", thus producing a scale ranging from 3 to 15 . In this study, the reliability of the questionnaire, measured by Cronbach's alpha, was 0.665 (acceptable).

The next section, concerning positive and negative aspects of work, contained a question on job satisfaction, expressed on a 7-point Likert scale ranging from extremely dissatisfied to extremely satisfied, according to Warr et al. [19]; a question about happiness, on a 10-point scale, according to Abdel-Khalek [20]; a question on burnout, on a 6-point scale, according to West et al. [21], and finally a question regarding the possibility of leaving the hospital [yes/no].

Psychological symptoms were measured with the Italian version [22] of the "Goldberg Anxiety and Depression Scale" (GADS) [23], composed of 18 binary items on anxiety (9 items) and depression (9 items). Typical questions were: "Have you had difficulty relaxing?" for anxiety, and "Have you felt lethargic?" for depression. Persons with an anxiety score of 5 points or more, or a depression score of 2 or more, were classified as potentially anxious. In this study, the reliability of the GADS subscales, measured by Cronbach's alpha, was 0.784 for anxiety and 0.693 for depression (acceptable).

Sleep quality was measured with the 2-item version of the "Sleep Condition Indicator" (SCI-02) $[24,25]$, which aims to assess insomnia according to the Diagnostic Statistic Manual 5 (DSM5). Each 
question was graded on a 5-point Likert scale, ranging from 4 to 0 . The final score ranged between 0 and 8 , with higher values indicating better sleep quality. Cronbach's alpha was 0.814 (good). A score of $\leq 4$ revealed possible insomnia disorder.

\subsection{Statistics}

The variables were analyzed in descriptive terms, mean and standard deviation for continuous variables, frequency for categorical variables. The results obtained in the second wave were compared with those of the first wave by Student's t test for continuous variables, Mann Whitney's test for ordinal variables, chi square test for categorical variables.

The role of pandemic-induced changes on occupational stress level was investigated using a stepwise linear regression model. The independent variables included in the model were: gender; age; physical activity; meditation; procedural justice; workload; monotony; compassion fatigue; isolation at work; social loneliness. The perceived effort-reward imbalance was set as a dependent variable. In the stepwise method based on the $\mathrm{p}$-value of $\mathrm{F}$, the model starts by entering the variable with the smallest $\mathrm{p}$-value (PIN p $<0.05$ ), it then adds the second strongest predictor with the smallest $\mathrm{p}$-value for $\mathrm{F}$ and so on. Variables already in the equation are removed if their $\mathrm{p}$-value becomes larger than the default limit (POUT $p>0.1$ ) due to the inclusion of another variable.

The relationship between perceptions of justice and stress and outcomes was studied by simple linear regression analysis for continuous variables (sleep quality, anxiety, and depression) and logistic regression for binary variables (sleepless, anxious, depressed, satisfied, happy, with burnout, willing to leave work).

Analyses were performed using IBM/SPSS 26.0 (IBM Corporation, Armonk, NY, USA).

\section{Results}

When questioned about changes in their work due to the pandemic, workers reported a significant increase in workload and compassion fatigue resulting from the need to inform relatives of the death of a patient. These problems, which had already been described in the survey conducted during the first wave, were reported with a significantly increased frequency in the second wave (Table 2). Most workers complained of having to work in isolation, and of being severely isolated in their social life (Table 2). Workers also reported a major change in public opinion between the first and second phases of the pandemic. Nine out of ten (87.4\%) observed that in the first phase of the epidemic, between March and May 2020, people expressed appreciation and trust in HCWs, while in the current stage (December 2020), 91.0\% believed HCWs were viewed less favorably than in the past.

As for the factors that increase resilience, free time spent on physical activity and meditation was reduced or seriously reduced for most of the participants $(81.8 \%$ and $67.9 \%$ for physical and spiritual activities, respectively) (Table 2). About one third of the participants (31.5\%) did not believe that meditative prayer could lead to spiritual wellbeing or that it was an important part of life. A favorable attitude towards prayer had a weak correlation with occupational rewards (Spearman's rho $=0.180$, $\mathrm{p}=0.03)$.

Table 2. Changes reported during the COVID-19 outbreak, and prevalence of high stress, insomnia, anxiety, and depression during the $1^{\text {st }}$ and $2^{\text {nd }}$ wave.

\begin{tabular}{cccccc}
\hline \multirow{2}{*}{ Reported effect } & \multicolumn{3}{c}{$1^{\text {st }}$ wave } & \multicolumn{3}{c}{ 2nd $^{\text {nd }}$ wave } \\
& $\mathrm{N}$ & $\%$ & $\mathrm{~N}$ & $\%$ & $p$ \\
\hline Increased/greatly increased workload & 94 & 52.2 & 126 & 88.1 & .000 \\
The work became more repetitive and monotonous & 54 & 30.6 & 43 & 30.1 & .589 \\
More frequent need to inform of the death of a relative & 56 & 36.7 & 88 & 61.6 & .000 \\
Isolation at work & - & - & 72 & 50.4 & \\
Isolation in life & - & - & 115 & 80.5 & \\
Time for physical exercise was shorter/much shorter & 141 & 88.3 & 117 & 81.8 & .099 \\
Time for meditation was shorter/much shorter & 87 & 48.3 & 97 & 67.9 & .000 \\
High stress (effort/reward weighted ratio $>1$ ) & 139 & 77.2 & 118 & 83.1 & .192 \\
\hline
\end{tabular}




\begin{tabular}{cccccc}
\hline Insomniac (SCI08 score $\leq 16 ;$ SCI02 score $\leq 4)$ & 79 & 43.9 & 57 & 40.1 & .499 \\
Anxious (GADS anxiety score $\geq 5$ ) & 45 & 25.0 & 45 & 31.3 & .212 \\
Depressed (GADS depression score $\geq 2)$ & 89 & 49.4 & 90 & 62.5 & .019 \\
\hline
\end{tabular}

SCI08= Sleep Condition Indicator; SCI02= Sleep Condition Indicator, short form, two items; GADS=

Goldberg Anxiety and Depression Scale

The perception of justice in safety procedures (range 3-15) yielded an average value of 7.90 \pm 2.26 , considerably lower than the maximum. The average value was located at the 53rd percentile. In the survey conducted during the first wave, the perception of justice was measured on a scale containing a larger number of items than was used in the second wave. Also in the first survey, the mean response was found to be in the 53rd percentile (Table 3).

An analysis of the occupational stress perceived by workers indicated, on average, a prevalence of the effort made to work over the material and intangible rewards received. Effort (range 3-12) was on average $9.64 \pm 1.66$, i.e., about $80 \%$ of the maximum. Effort increased significantly in the second wave compared to the first ( $p<0.001$ ). Reward (range $7-28$ ) was $16.01 \pm 4.08$, close to $57 \%$ of the maximum score: no significant increase was observed compared to previously recorded reward levels. Consequently, mean ERI was $1.54 \pm 0.63$, and the vast majority of workers $(118,83.1 \%)$ were in a state of distress. The situation confirmed and underlined what had been observed in the first phase, with a very significant statistical increase in occupational stress (Table 3).

The average quality of sleep, measured by the SCI02 (range $0-8)$, was low $(5.22 \pm 2.39,65 \%$ of the maximum score); and a large number of workers $(105,73.9 \%)$ suffered from insomnia. The number of workers who could be classified as "suffering from insomnia" was substantially similar to the estimate made in the first wave. Mean anxiety and depression scores, measured with GADS, were moderately high for anxiety (3.39 \pm 2.45$)$, and particularly high for depression (2.74 \pm 2.06$)$. According to the diagnostic criteria of the questionnaire, 45 workers (31.3\%) were likely to suffer from clinically relevant anxiety syndrome and $90(62.5 \%)$ from depression. Compared to the first wave, there was a slight but not significant increase in mean anxiety scores, whereas the increase in the mean score and number of cases for depression was very significant (Tables 2 and 3).

Table 3. Mental health indicators: (perceived justice, occupational stress, sleep quality, anxiety, depression) in anesthesiologists during the $1^{\text {st }}$ and $2^{\text {nd }}$ wave of the COVID-19 outbreak.

\begin{tabular}{cccc}
\hline Variable & $\begin{array}{c}1^{\text {st }} \text { wave } \\
\text { Mean } \pm \text { s.d. } \\
(\% \max )\end{array}$ & $\begin{array}{c}2^{\text {nd }} \text { wave } \\
\text { Mean } \pm \text { s.d. } \\
(\% \max )\end{array}$ & $p$ \\
\hline \multirow{2}{*}{ Procedural Justice* } & $31.8 \pm 7.3$ & $7.9 \pm 2.3$ & \\
& $(52.8 \%)$ & $(52.7 \%)$ & \\
Effort & $8.6 \pm 1.9$ & $9.6 \pm 1.7$ & .000 \\
& $(71.7 \%)$ & $(80.0 \%)$ & \\
Reward & $16.5 \pm 3.6$ & $16.0 \pm 4.1$ & .251 \\
Job stress & $(58.9 \%)$ & $(57.1 \%)$ & \\
Sleep quality & $1.31 \pm 0.49$ & $1.54 \pm 0.63$ & .000 \\
Anxiety & $21.2 \pm 8.2$ & $4.78 \pm 2.38$ & \\
Depression & $(66.2 \%)$. & $(59.7 \%)$ & \\
& $3.04 \pm 2.29$. & $3.39 \pm 2.45$ & .193 \\
\hline
\end{tabular}

${ }^{*}$ A different number of items was used during the $1^{\text {st }}$ and $2^{\text {nd }}$ survey.

The mean score for occupational satisfaction, measured as indicated by Warr et al. on a scale ranging from extremely dissatisfied to extremely satisfied, was $4.05 \pm 1.48$, corresponding to "I am uncertain". $51.4 \%$ of the workers were moderately, very or extremely satisfied. The average score for happiness in life, measured on a scale from 1 to 10, was $6.46 \pm 1.97$. Asked how often workers experienced burnout - an occupational condition characterized by emotional exhaustion, 
depersonalization and a low sense of personal achievement - the average response was $3.56 \pm 1.58$. This level corresponded to the "several times a month" option.

To the question 'Have you thought about leaving this job?' 60 workers $(42.6 \%)$ answered affirmatively.

The association between occupational changes brought about by the pandemic and work-related stress was studied by stepwise linear regression. The resulting model, which explained a significant share of the variability $(\mathrm{R} 2=0.34)$ indicated that stress was dependent on lack of procedural justice, increased workload, isolation at work (having to work alone), and lack of time for meditation and relaxation. Gender and age were not included in the model. Similarly, monotony, compassion fatigue, social loneliness and physical activity were excluded from the model (Table 4).

Table 4. $2^{\text {nd }}$ wave. Stepwise linear regression analysis. Relationship between job changes and perceived work-related stress (ERI).

\begin{tabular}{ccc}
\hline Variable & \multicolumn{2}{c}{ ERI } \\
\cline { 2 - 3 } & Standardized Beta & $p$ \\
\hline Procedural Justice & -0.310 & 0.001 \\
Workload & 0.270 & 0.001 \\
Isolation at work & 0.199 & 0.007 \\
Meditation & -0.151 & 0.034 \\
\hline Determination coefficient of the model $\left(\mathrm{R}^{2}\right)$ & 0.343 \\
\hline
\end{tabular}

Variables excluded from the model: Gender; Age class: Monotony; Compassion fatigue; Social loneliness; Physical activity.

The relationship between perceived justice, occupational stress and mental health outcomes was studied using simple linear regression models. Effort was a highly significant predictor of low sleep quality, anxiety, and depression. (Table 5).

Table 5. 2nd wave. Health outcomes associated with procedural justice and occupational stress. Linear regression analysis adjusted for age and gender.

\begin{tabular}{ccccccc}
\hline \multirow{2}{*}{ Variable } & $\begin{array}{c}\text { Sleep quality } \\
\text { Standardized } \\
\text { Beta }\end{array}$ & $p$ & $\begin{array}{c}\text { Anxiety } \\
\text { Standardized } \\
\text { Beta }\end{array}$ & $p$ & \multicolumn{3}{c}{ Depression } \\
& .169 & .062 & -.110 & .220 & .065 & .453 \\
Betandardized & $p$ \\
\hline Procedural justice & -.349 & .000 & .345 & .000 & .364 & .000 \\
Effort & .059 & .521 & -.067 & .464 & -.151 & .091 \\
Reward & & & & &
\end{tabular}

Effort significantly increased the odds of being diagnosed as insomniac, anxious, depressed, or burned out, and significantly reduced the odds of being satisfied and happy. On the other hand, the perception of Procedural Justice had a protective effect on insomnia, while Reward significantly increased the odds of work satisfaction. The intention to leave the hospital was significantly predicted by Effort, while Reward was a strong protective factor (Table 6).

Table 6. 2nd wave. Health outcomes associated with procedural justice and occupational stress. Multivariate logistic regression model adjusted for age and gender.

\begin{tabular}{ccccccc}
\hline \multirow{2}{*}{ Variable } & \multicolumn{2}{c}{ Insomniac $^{1}$} & \multicolumn{2}{c}{ Anxious $^{2}$} & \multicolumn{3}{c}{ Depressed $^{3}$} \\
& OR (CI95\%) & $p$ & OR (CI95\%) & $p$ & OR (CI95\%) & $p$ \\
\hline \multirow{2}{*}{ Procedural justice } & $\mathbf{0 . 7 9 4}$ & .029 & .950 & .639 & 0.980 & .838 \\
Effort & $(0.646,0.977)$ & & $(0.766,1.177)$ & & $(0.805,1.193)$ & \\
& $\mathbf{1 . 7 8 0}$ & .000 & $\mathbf{1 . 8 5 8}$ & .000 & $\mathbf{1 . 3 6 3}$ & .015 \\
\hline
\end{tabular}




\begin{tabular}{|c|c|c|c|c|c|c|}
\hline Reward & $\begin{array}{c}(1.342,2.360) \\
1.053 \\
(0.942,1.178 \\
\end{array}$ & .365 & $\begin{array}{c}(1.360,2.539) \\
0.951 \\
(0.841,1.075) \\
\end{array}$ & .421 & $\begin{array}{c}(1.063,1.748) \\
0.956 \\
(0.857,1.067) \\
\end{array}$ & .420 \\
\hline \multirow{2}{*}{ Variable } & \multicolumn{2}{|c|}{ Satisfied $^{4}$} & Happy $^{5}$ & \multirow[b]{2}{*}{$p$} & \multicolumn{2}{|c|}{ Burned out ${ }^{5}$} \\
\hline & OR (CI95\%) & $p$ & OR (C195\%) & & OR (C195\%) & $p$ \\
\hline Procedural justice & $\begin{array}{c}1.006 \\
(0.806-1.257\end{array}$ & .955 & $\begin{array}{c}0.911 \\
(0.755,1.100)\end{array}$ & .334 & $\begin{array}{c}1.083 \\
(0.873,1.344)\end{array}$ & .467 \\
\hline Effort & $\begin{array}{c}\mathbf{0 . 5 1 5} \\
(0.375,0.706,)\end{array}$ & .000 & $\begin{array}{c}\mathbf{0 . 7 7 1} \\
(0.604,0.983)\end{array}$ & .036 & $\begin{array}{c}\mathbf{1 . 9 1 8} \\
(1.398,2.631)\end{array}$ & .000 \\
\hline Reward & $\begin{array}{c}\mathbf{1 . 2 7 7} \\
(1.115,1.463) \\
\end{array}$ & .000 & $\begin{array}{c}1.103 \\
(0.991,1.227) \\
\end{array}$ & .073 & $\begin{array}{c}0.940 \\
(0.834,1.060) \\
\end{array}$ & .312 \\
\hline \multicolumn{7}{|c|}{ Intention to leave } \\
\hline Variable & OR (CI95\%) & $p$ & & & & \\
\hline Procedural justice & $\begin{array}{c}1.049 \\
(0.859,1.281)\end{array}$ & 639 & & & & \\
\hline Effort & $\begin{array}{c}\mathbf{1 . 4 1 3} \\
(1.077,1.852)\end{array}$ & .012 & & & & \\
\hline Reward & $\begin{array}{c}\mathbf{0 . 7 9 2} \\
(0.699,0.896)\end{array}$ & .000 & & & & \\
\hline
\end{tabular}

Notes: $1=$ SCI02 score $\leq 4 ; 2=$ GADS anxiety score $\geq 5$; 3=GADS depression score $\geq 2$; $4=$ moderately, very, or extremely satisfied; $5=$ dichotomized at the median.

\section{Discussion}

This study, which is the second cross-sectional survey on frontline workers in a COVID-19 hub hospital in Rome where the baseline interview took place during the first wave of the outbreak [ref], illustrates how the mental health of these workers evolved in relation to the pandemic. The high workload, isolation at work, uncertainty about safety procedures and the sharp reduction in the time devoted to meditation and relaxation have led to a significant increase in occupational stress, which for over $80 \%$ of workers is characterized by a discrepancy between the effort made to work and the material and immaterial rewards received as a result of work.

At ten months from the outbreak of the COVID epidemic, this continual state of tension has led to a high rate of sleep and anxiety disorders and low levels of job satisfaction and happiness. Between the first and second wave of the pandemic, the most alarming factor is the increase in cases of depression. More than $60 \%$ of workers have a score exceeding the cut-off level, corresponding to a $50 \%$ chance of being diagnosed as "depressed" when examined by a specialist. Over $40 \%$ of workers considered quitting their job, and about a quarter of those who took part in the first survey no longer worked in the hospital.

Our study demonstrates the effect the COVID-19 pandemic has had on the mental health of intensivists. To the best of our knowledge, this is the first study that has used a repeated crosssectional design to evaluate changes in the level of mental health induced by the prolonged duration of the pandemic. We are convinced that our study can make a substantial contribution to the consolidation of evidence concerning the effects of the pandemic on the mental health of HCWs.

Some of the factors found to be associated with occupational stress in our survey were reported in previous research. For example, excessive workload [26], isolation or lack of support at work [27], the lack of procedural justice or insufficient information about the outbreak and protective measures [28] were found to increase stress in frontline HCWs. Our research revealed that lack of time for meditation was strongly associated with stress. It is well known that meditation can significantly increase workers' resilience [29] and meditative prayer has been used to prevent burnout in workers [30]. Mindfulness techniques have been used to support HCWs struggling with COVID-19 [31]. Moreover, in our study a positive attitude towards prayer was associated with greater Reward; this 
result is in agreement with the observation of a Taiwanese team, indicating the positive effect of religion on psychological resilience in HCWs during the pandemic [32].

The effects found in our cohort correspond to those reported by other researchers: insomnia [33], anxiety [6], burnout [34], reduced happiness [35], lack of job satisfaction and turnover intention [36] are common in HCWs. Many of these outcomes remained constant in our cohort between the first and second wave and it is not easy to understand whether they were a result of the pandemic or were already present in the population. However, we observed a significant increase in workload and compassion fatigue, and a further reduction in the time devoted to meditation and mental activities between the first and second waves. These factors were accompanied by an increase in what were already very frequent cases of depression, especially among the younger sector of the population. In fact, this has now become the dominant condition, concerning 6 out of $10 \mathrm{HCWs.}$

The main strength of this study lies in its prospective design, the only one that enables us to record how the perception of stress and the mental health of workers have evolved in relation to the pandemic. The weakness inherent in the survey method is that no objective verification can be made of the reliability of the answers provided. The brevity of the questionnaire was a further limitation: it had to be very short, because the frontline workers had very little time to devote to responding and, if they interrupted the survey, the system prevented them from continuing the compilation. For this reason, in this second survey, we adopted the short form of the procedural justice and sleep quality scales, in order to restrict compilation time to within 7 minutes without omitting to measure the variables of interest.

The protection of mental health in HCWs is of paramount importance for ensuring quality care [ref]. We are convinced that preventive intervention is urgently required and that, in addition to individual support action aimed at increasing resilience, this should include a series of structural provisions designed to increase the workforce, optimize production flows, lower workloads and provide greater rewards.

Author Contributions: Conceptualization, N.M. and P.M.S.; methodology, N.M.; formal analysis, N.M.; investigation, P.M.S.; resources, N.M.; data curation, N.M.; writing - original draft preparation, N.M.; writingreview and editing, N.M.; supervision, M.A.; All authors have read and agreed to the published version of the manuscript.

Funding: This research received no external funding.

Acknowledgments: We thank all the participants who kindly responded to the survey. We also thank E.A. Wright, who revised the English language.

Conflicts of Interest: The authors declare no conflict of interest.

\section{References}

1. Magnavita, N.; Sacco, A.; Chirico, F. Covid-19 pandemic in Italy: Pros and cons. ZNOZ Zdr Publiczne I Zarz. 2020, 18 (1). http://dx.doi.org/10.4467/20842627OZ.20.002.12656.

Available online: https://www.ejournals.eu/Zdrowie-Publiczne-i-Zarzadzanie/202/Tom-18-zeszyt1/art/17398/ (accessed on February 20, 2021)

2. Chirico, F.; Sacco, A.; Nucera, G.; Magnavita, N. (2021) Coronavirus disease 2019: the second wave in Italy. JHR Journal of Health Research, ahead-of-print. https://doi.org/10.1108/IHR-10-2020-0514

3. De Kock, J.H.; Latham, H.A.; Leslie, S.J.; Grindle, M.; Munoz, S.A.; Ellis, L.; Polson, R.; O'Malley, C.M. A rapid review of the impact of COVID-19 on the mental health of healthcare workers: implications for supporting psychological well-being. BMC Public Health. 2021, 21(1):104. doi: 10.1186/s12889-020-10070-3.

4. Magnavita, N.; Tripepi, G.; Di Prinzio, R.R. Symptoms in Health Care Workers during the COVID-19 Epidemic. A Cross-Sectional Survey. Int. J. Environ. Res. Public Health 2020, 17, 5218, https://doi.org/10.3390/ijerph17145218-20 Jul 2020.

5. Magnavita, N.; Chirico, F.; Sacco, A. Covid-19, from hospitals to courts. The Lancet 2021 Published Online, April 14, 2021 https://doi.org/10.1016/S0140-6736(21)00678-4

6. Pappa, S.; Ntella, V.; Giannakas, T.; Giannakoulis, V.G.; Papoutsi, E.; Katsaounou, P. Prevalence of depression; anxiety; and insomnia among healthcare workers during the COVID-19 pandemic: A systematic review and meta-analysis. Brain Behav. Immun. 2020, 88:901-907. doi:10.1016/j.bbi.2020.05.026. 
7. Vindegaard, N.; Benros, M.E. COVID-19 pandemic and mental health consequences: Systematic review of the current evidence. Brain Behav. Immun. 2020, doi:10.1016/j.bbi.2020.05.048.

8. Wu, T.; Jia, X.; Shi, H.; Niu, J.; Yin, X.; Xie, J.; Wang, X. Prevalence of mental health problems during the COVID-19 pandemic: A systematic review and meta-analysis. J Affect Disord. 2021, 281:91-98. doi: 10.1016/j.jad.2020.11.117

9. Magnavita, N.; Di Prinzio, R.R.; Chirico, F.; Sacco, A.; Quintavalle, G. COVID-19 and staff mental health: Is there an evidence? An Italian field study. Eur. J. Public Health 2020, 30 (Suppl. 5), ckaa165.565.

10. Magnavita, N.; Soave, P.M.; Ricciardi, W.; Antonelli, M. Occupational stress and mental health of anaesthetists during the COVID-19 pandemic. Int J Environ Res Public Health 2020, 17, 8245; doi:10.3390/ijerph17218245

11. Magnavita, N.; Soave, P.M.; Antonelli, M. Teaching safety. The well-being of resident anaesthetists at the forefront of COVID-19. (submitted)

12. Magnavita, N.; Garbarino, S.; Siegrist, J. The use of parsimonious questionnaires in occupational health surveillance. Psychometric properties of the short Italian version of the Effort/Reward Imbalance questionnaire. TSWJ Sci. World J. 2012; 2012: 372852, doi:10.1100/2012/372852.

13. Siegrist, J. Adverse health effects of high-effort/low-reward conditions. J. Occup. Health Psychol. 1996, 1, $27-41$.

14. Siegrist, J.; Wege, N.; Puhlhofer, F.; Wahrendorf, M. A short generic measure of work stress in the era of globalization: Effort-reward imbalance. Int. Arch. Occup. Environ. Health 2009, 82, 1005-1013.

15. Magnavita, N.; Bergamaschi, A. Justice at the workplace. Validation of the Italian version of Colquitt's justice measurement questionnaire (JM20). G Ital. Med. Lav. Ergon. 2008, 30 (Suppl. 2), 449-450.

16. Elovainio, M.; Heponiemi, T.; Sinervo, T.; Magnavita, N. Organizational justice and health; review of evidence. G. Ital. Med. Lav. Ergon. 2010, 32, B5-B9.

17. Colquitt, J.A. On the dimensionality of organizational justice: A construct validation of a measure. J. Appl. Psychol. 2001, 86, 386-400.

18. Elovainio, M.; Heponiemi, T.; Kuusio, H.; Sinervo, T.; Hintsa, T.; Aalto, A.M. Developing a short measure of organizational justice: A multisample health professionals study. J. Occup. Environ. Med. 2010, 52, 1068-1074, doi:10.1097/JOM.0b013e3181f8447c.

19. Warr, P.; Cook, J.; Wall, T. Scales for the measurement of some work attitudes and aspects of psychological well-being. J Occup Psychol 1979; 52: 129-148

20. Abdel-Khalek, A.M. Measuring happiness with a single-item scale. Social Behavior and Personality: An international journal, 2006, 34, 139-150. DOI: https://doi.org/10.2224/sbp.2006.34.2.139

21. West, C.P.; Dyrbye, L.N.; Satele, D.V.; Sloan, J.A.; Shanafelt, T.D. Concurrent validity of single-item measures of emotional exhaustion and depersonalization in burnout assessment. J Gen Intern Med. 2012, 27(11):1445-52. doi: 10.1007/s11606-012-2015-7.

22. Magnavita, N. Anxiety and depression at work. The A/D Goldberg Questionnaire. G Ital. Med. Lav. Ergon. 2007, 29, 670-671.

23. Goldberg, D.; Bridges, K.; Duncan-Jones, P.; Grayson, D. Detecting anxiety and depression in general medical settings. BMJ 1988. 297, 897-899.

24. Espie, C.A.; Kyle, S.D.; Hames, P.; Gardani, M.; Fleming, L.; Cape, J. The Sleep Condition Indicator: A clinical screening tool to evaluate insomnia disorder. BMJ Open 2014, 4, e004183, doi:10.1136/bmjopen-2013-004183.

25. Palagini, L.; Ragno, G.; Caccavale, L.; Gronchi, A.; Terzaghi, M.; Mauri, M.; Kyle, S.; Espie, C.A.; Manni, A. Italian validation of the Sleep Condition Indicator: A clinical screening tool to evaluate Insomnia Disorder according to DSM-5 criteria. Int. J. Psychophysiol. 2015, 98 Pt 1, 435-440, doi:10.1016/j.ijpsycho.2015.08.008.

26. Marvaldi, M.; Mallet, J.; Dubertret, C.; Moro, M.R.; Guessoum, SB. Anxiety, depression, trauma-related, and sleep disorders among healthcare workers during the COVID-19 pandemic: A systematic review and metaanalysis. Neurosci Biobehav Rev. 2021,126:252-264. doi: 10.1016/j.neubiorev.2021.03.024.

27. Cabarkapa, S.; Nadjidai, S.E.; Murgier, J.; Ng, C.H. The psychological impact of COVID-19 and other viral epidemics on frontline healthcare workers and ways to address it: A rapid systematic review. Brain Behav Immun Health. 2020, 100144. doi: 10.1016/j.bbih.2020.100144.

28. Sirois, F.M.; Owens, J. Factors Associated With Psychological Distress in Health-Care Workers During an Infectious Disease Outbreak: A Rapid Systematic Review of the Evidence. Front Psychiatry. 2021,11:589545. doi: 10.3389/fpsyt.2020.589545.

29. Pérez-Fuentes, M.d.C.; Molero Jurado, M.d.M.; Mercader Rubio, I.; Soriano Sánchez, J.G.; Gázquez Linares, J.J. Mindfulness for Preventing Psychosocial Risks in the Workplace: A Systematic Review and Meta-Analysis. Appl. Sci. 2020, 10, 1851. https://doi.org/10.3390/app10051851 
30. Chirico, F.; Sharma, M.; Zaffina, S.; Magnavita, N. Spirituality and Prayer on Teacher Stress and Burnout in an Italian Cohort: A Pilot, Before-After Controlled Study. Front Psychol. 2020, 10:2933. doi: 10.3389/fpsyg.2019.02933.

31. Lai, K.S.P.; Watt, C.; Ionson, E.; Baruss, I.; Forchuk, C.; Sukhera, J.; Burhan, A.M.; Vasudev, A. Breath Regulation and yogic Exercise An online Therapy for calm and Happiness (BREATH) for frontline hospital and long-term care home staff managing the COVID-19 pandemic: A structured summary of a study protocol for a feasibility study for a randomised controlled trial. Trials. 2020;21(1):648. doi: 10.1186/s13063-020-04583w.

32. Chang, M.C.; Chen, P.F.; Lee, T.H.; Lin, C.C.; Chiang, K.T.; Tsai, M.F.; Kuo, H.F.; Lung, F.W.. The Effect of Religion on Psychological Resilience in Healthcare Workers During the Coronavirus Disease 2019 Pandemic. Front Psychol. 2021, 12:628894. doi: 10.3389/fpsyg.2021.628894.

33. Jahrami, H.; BaHammam, A.S.; Bragazzi, N.L.; Saif, Z.; Faris, M.; Vitiello, M.V. Sleep problems during the COVID-19 pandemic by population: a systematic review and meta-analysis. J Clin Sleep Med. 2021,17(2):299313. doi: $10.5664 /$ jcsm. 8930 .

34. Magnavita, N.; Chirico, F.; Garbarino, S.; Bragazzi, N.L.; Santacroce, E.; Zaffina, S. SARS/MERS/SARS-CoV-2 Outbreaks and Burnout Syndrome among Healthcare Workers. An Umbrella Systematic Review. Int. J. Environ. Res. Public Health 2021, 18(8), 4361; https://doi.org/10.3390/ijerph18084361

35. Wang, J.; He, J.; Zhu, J.; Qiu, J.; Wang, H.; Xu, H. Qualitative study on working experience of COVID-19 care nurses. Zhejiang Da Xue Xue Bao Yi Xue Ban. 2020;49(4):480-486. doi: 10.3785/j.issn.1008-9292.2020.08.07.

36. Labrague, L.J.; de Los Santos, J.A.A. Fear of COVID-19, psychological distress, work satisfaction and turnover intention among frontline nurses. J Nurs Manag. 2021, 29(3):395-403. doi: 10.1111/jonm.13168.

37. Chirico, F.; Nucera, G.; Magnavita, N. Protecting the mental health of healthcare workers during the COVID19 emergency. (Editorial). Brit J Psych Int 2020 doi:10.1192/bji.2020.39

38. Chirico, F.; Nucera, G.; Magnavita, N. COVID-19: Protecting Healthcare Workers is a priority. Infect Control Hosp Epidemiol. 2020,41(9):1117. doi: 10.1017/ice.2020.148

Publisher's Note: MDPI stays neutral with regard to jurisdictional claims in published maps and institutional affiliations.

(C) 2020 by the authors. Submitted for possible open access publication under the terms and conditions of the Creative Commons Attribution (CC BY) license (http://creativecommons.org/licenses/by/4.0/). 